\title{
THE INFLUENCES OF RECOVERY ON LOW BACK PAIN DEVELOPMENT: A THEORETICAL MODEL
}

TOBIAS MIERSWA ${ }^{1}$ and MICHAEL KELLMANN ${ }^{1,2}$

\author{
${ }^{1}$ Ruhr University, Bochum, Germany \\ Unit of Sport Psychology, Faculty of Sport Science \\ ${ }^{2}$ The University of Queensland, Queensland, Australia \\ Schools of Human Movement Studies and Psychology
}

\begin{abstract}
Psychologically and physically straining work conditions increase the risk of low back pain (LBP) development. According to recent recovery theories, leisure time recovery can counteract the negative influences of work stress on health. Similarly, a recent empirical work has indicated a moderating role of recovery on the link between stress and health issues. In this paper, a theoretical model is deduced to integrate the moderating effects of recovery on work stress and LBP development. Based on theoretical and empirical results, 2 separate recovery paths are distinguished: on the one hand, recovery can prevent the experience of stress because a well-recovered person can cope more easily with work demands; while on the other hand, recovery refills the depleted resources after confrontation with work strain and reduces stress experiences. Given that work strains is a main risk factor for LBP development, recovery in leisure time seems to be a highly relevant aspect, which has not been investigated to date in the field of LBP.
\end{abstract}

Key words:

Recovery, Low back pain, Work stress, Psychosocial risk factors, Leisure time

\section{INTRODUCTION}

Low back pain (LBP) is a serious health issue causing high financial burden [1-3]. The direct costs of LBP, including money spent on medical care, medications, diagnostic testing, etc., account for only $12.5 \%$ of the total costs, with the remaining $87.5 \%$ involving indirect costs originating from work absence and reduced productivity. An overview of LBP costs for several countries can be found in Dagenais, Caro, and Haldeman [4].

Numerous studies have been conducted to identify risk factors for LBP development. Results regarding these LBP risk factors have revealed the influence of variables in a variety of areas, including demographic, social, psychological, physical, and biological factors [5]. Low back pain is therefore considered as a multicausal phenomenon. Apart from physical work demands [6], psychosocial characteristics of working environments are among the most frequently investigated risk factors related to $\operatorname{LBP}[7,8]$. Research results show an increased LBP risk for employees with straining work conditions, caused by high work demands and low work resources [9-12]. The overall work strain and the resulting stress perceived by workers play a central role in the process of LBP developing, as described by Marras [13].

The theoretical deliberations of this article have been compiled within the framework of the project "Rückenschmerz" (IIA1-080102B/11-14), initiated and funded by the German Federal Institute of Sport Science and realized within MiSpEx - the National Research Network for Medicine in Spine Exercise.

Received: March 26, 2014. Accepted: July 22, 2014.

Corresponding author: T. Mierswa, Unit of Sport Psychology, Faculty of Sport Science, Ruhr University Bochum, Gesundheitscampus Nord 10, 44801 Bochum, Germany (e-mail: tobias.mierswa@rub.de). 
Research in the field of LBP development to date has focused on possible risk factors promoting LBP development, especially regarding work conditions. However, according to basic health concepts such as the salutogenesismodel [14], not only risk factors but also protective factors should be taken into account when health issues are investigated. Furthermore, work-health models emphasize the importance of recovery experiences in the relation of work strains with health issues or general well-being $[15,16]$. However, the influences of recovery processes have hitherto been neglected in theoretical and empirical work regarding LBP pathogenesis. Some researchers have started to investigate the influences of recovery experiences in leisure-time on the perception of psychosocial work factors and relations with health issues. Overall, these studies have indicated a protective effect of recovery in respect to experiencing work stress, as well as negative influences of straining work conditions on well-being and health. If recovery could protect workers from experiencing work stress, it should also be explored which influences recovery experiences have on the link between work-related LBP risk factors and LBP development.

Therefore, the purpose of this paper is to specify the role and function of recovery experience in the process of LBP development. The 1st section of this paper will provide a brief overview of most relevant psychosocial risk factors and the way in which they induce back pain. The following section contains the description of theoretical considerations regarding influences of recovery on work strain and health. Studies investigating these theoretical assumptions are presented in the 3rd section. Finally, a theoretical model for the influences of recovery experiences on LBP development will be derived.

\section{PSYCHOSOCIAL RISK FACTORS OF LBP}

Psychosocial factors play an important role in LBP development and have been investigated in a number of studies. In most of these studies, work-related psychosocial factors have been investigated. Two recent meta-analyses by Lang et al. [8] and Hauke et al. [7] identified high qualitative work demands, high work strain, and monotonous work as relevant LBP risk-factors. Furthermore, Hauke et al. [7] also reported low job control as increasing LBP risk.

The identified LBP risk factors can be separated into 2 distinct groups. Work demands include factors at work which increase the effort that employees have to invest to successfully fulfill their duties. A confrontation with high work demands at work will therefore result in an increase of psychological and physiological costs. In contrast, work resources include work factors supporting employees, thereby reducing their work demands and the physical and psychological costs. Based on this model, LBP risk factors can be separated according to these 2 groups of work demands (quantitative work demands, monotonous work) and work resources (job control, job satisfaction, social support). The interactions between work demands and work resources lead to work strain perceived by employees, as described in the 'job demands-resources model' (JD-R model) [17]. This means that work strain, another LBP risk factor, can be understood as a consequence of demanding work conditions. Those interactions between work demands and resources are also confirmed for several LBP risk factors [5,18]. For instance, job control diminishes the effects of work demands on the LBP risk $[10,19,20]$.

Taking everything into account, all work demands have been reported to increase the risk of LBP when they are high, whereas work resources increase LBP risk when they are low. As a consequence of high work demands and low work resources, employees experience work strain. High work strain induces physical and psychological stress reactions, which are thought to enhance LBP development [13]. The described relations between psychosocial work factors and LBP development are summarized in Figure 1. The presented results and theoretical considerations emphasize the relevance of psychosocial work factors and particularly work strain for LBP development. 


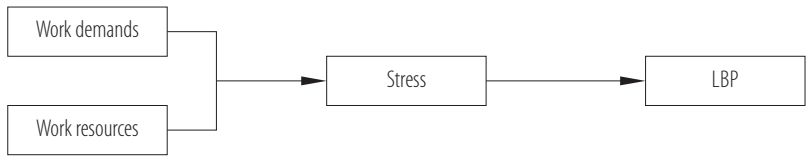

Fig. 1. Influence of work factors on low back pain (LBP) development

Apart from work-related factors, only a few additional psychosocial factors have been investigated as risk factors for LBP. Similar to work demands, additional burdens during leisure time, such as housework or caring for relatives, contribute to the risk of developing LBP [21,22]. More generally, Thorbjornsson et al. [23] reported that persons with unsatisfactory leisure time and unsatisfactory social contacts outside work show significantly more LBP phases in the following 24 years. They also found significant interactions between leisure time factors and work demands (see [23] for a detailed description). Similar to work factors, leisure time demands increase the risk of LBP, whereas leisure time resources, such as satisfaction with leisure time and sleep, reduce the risk. These results provide further support to the central role of strain and resulting stress reactions for LBP development, not only at work but also during leisure time. A possible mechanism through which psychological strain can be linked to the occurrence of LBP is explained in the work of Marras [13].

\section{WORK FACTORS, RECOVERY AND HEALTH}

Several models have described the influences of psychosocial work factors on health and well-being [15-17]. The model of Geurts and Sonnentag [15] holds particular interest for this paper. Their model combines the basic assumptions of the allostatic load theory of McEwen [24] and the 'effort recovery model' of Meijman and Mulder [16]. According to Geurts and Sonnentag [15], confrontation with work strain leads to physical and psychological adaptations (acute load reactions) because employees need to invest effort to perform successfully at work. These acute load reactions, often also described as acute stress reactions, are unavoidable yet reversible; namely, the psychological and physiological systems will return to their initial state when confrontation with straining work conditions is over. This process of restoring is named recovery. If one perceives further strain after work or has to ruminate about work in leisure time, load reactions will remain and no recovery can take place. The physical and psychological systems cannot return to their initial optimal state. Upcoming work demands will further increase these ongoing load reactions and are perceived as even more straining, due to the increased effort needed to cope with them. This could lead to a vicious circle and strong sustained load reactions, often described as stress. The ongoing chronic stress is associated with health issues and reduced well-being [15].

Kellmann [25] also described this accumulation of stress in his 'scissor model', outlining the interrelationship between stress and recovery. According to this model, one could handle stress up to an individually high level without compensation via additional recovery activities. If the perceived stress rises beyond this individual level, additional recovery demands are necessary to stop load reactions. One has to intentionally implement recovery activities in the daily routine because the automatic and unconscious recovery phases are no longer sufficient. As an increase in stress simultaneously reduces the opportunities for recovery, it becomes more difficult to achieve adequate recovery under high stress and accumulation of stress may occur. Over time, high amounts of stress or insufficient recovery could lead to health problems, such as burnout [26].

To sum up, the theoretical considerations support the idea of work factors playing an important role in the development of health issues because unfavorable work conditions could lead to work strain and stress. Moreover, the presented models highlight the importance of adequate and sufficient recovery to cope with upcoming work strains. Additional recovery should take place in leisure time, especially when work demands are unusually high. 
So far, no research has been undertaken to control for the influences of recovery processes on LBP development. However, if psychosocial work factors and work strain are related to the process of LBP development, influences of recovery on this relation should be investigated. It is necessary to take a closer look at the interrelation of recovery and relevant LBP risk factors to clarify the possible influences of recovery processes on LBP. Accordingly, the results concerning this interrelationship are described in the following section.

\section{WORK DEMANDS AND RECOVERY}

Most of the relevant risk factors of LBP are related to the need for recovery. Whereas work strain, work demands and high physical loads increase the need for recovery, job control, job satisfaction and sufficient sleep have the opposite effect [27-29]. Therefore, it can be concluded that straining work conditions with high demands and low resources increase the need for recovery.

The positive influence of adequate recovery on the ability to cope with following demands, as stated in the previously mentioned theoretical models, has also been confirmed in recent research. For instance, Binnewies, Sonnentag, and Mojza [30] indicated that the recovery state at the beginning of the week negatively predicts the perception of effort spent at work during the week. In particular, psychological detachment from work is important to reduce the perceived need of recovery [31-33]. Persons with a high recovery experience on vacation, at the weekend or in the evening showed a better performance during the following working days, as measured by self-rating scales and co-worker assessment [30,32,34-36]. Moreover, further non-work hassles at the weekend led to worse job performances during the next week in a study by Fritz and Sonnentag [37].

The presented results support the theoretical assumptions of recovery affecting the influence of work demands and resources on stress. On the one hand, high work demands

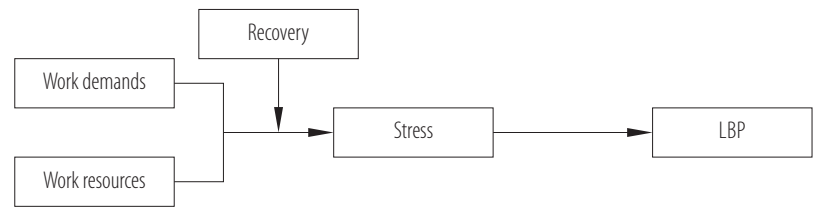

LBP - low back pain.

Fig. 2. Recovery influences on the interplay of work factors and stress

increase the need for recovery and feelings of being stressed. On the other hand, appropriate recovery leads to better performances and reduced stress effects generated by future demanding situations. A well-recovered person is more capable of dealing with forthcoming demands and will perceive less stress when confronted with these demands. Accordingly, recovery has a significant impact on the perception of and ability to cope with work factors, identified as relevant LBP risk factors. Therefore, it can be hypothesized that recovery could prevent LBP development by reducing the work strain and resulting stress reactions, as described in Figure 2.

\section{RECOVERY AND HEALTH}

Apart from interrelations between work conditions and recovery, the importance of recovery processes for prevention of health issues has also been indicated in several studies. Insufficient recovery is related to various health parameters, such as the risk of cardiovascular diseases [38,39], general health [40,41], well-being [34] or injuries $[42,43]$. In a study by Brink et al. [44], the stress and recovery states of soccer players predicted the occurrence of illness and injuries in the following 2 seasons. Soccer players with high amounts of stress and low recovery scores tend to suffer from injuries more often. Similarly, a correlation study of students during their exam period showed a strong relation between different recovery states (general recovery, physical recovery, and sleep) and physiological or psychological complaints [45]. Consistent with these results, persons with a high need for recovery 
were at twice the risk of sickness absence in the following 2 years, compared to people with high recovery status [46]. Furthermore, Sonnentag, Binnewies, and Mojza [47] indicated that, as an important recovery experience, the psychological detachment from work moderates the influence of work demands on psychosomatic health complaints. Only persons with low psychological detachment from work showed a positive relation between work demands and health complaints. In conclusion, the results of recent literature corroborate the positive influence of recovery on health. Recovery is necessary to prevent accumulation of stress over time, which is linked to the development of health complaints. Consequently, recovery is not only important to prevent the experience of high work strain, but also has a restoring function, as already stated in the model of Geurts and Sonnentag [15].

Researchers have started to investigate the influence of recovery on LBP. The occurrence of physical complaints, including LBP, was negatively related to general wellbeing, physical recovery, and sleep quality [45]. Similarly, de Jonge, Spoor, Sonnentag, Dormann, and van den Tooren [48] found people with low detachment values to show more physical health complaints in the previous 6 months, defined as neck, shoulder or back pain. The moderating influence of recovery has been investigated by Mierswa and Kellmann [49]. They reported a reduced back pain risk for employees with high detachment scores and, furthermore, interaction effects between detachment and work stressors and work climate. Employees showed an increased back pain risk when they reported strong work stressors or good work climate, but only when they had low scores on detachment. Employees with high detachment scores showed no increased risk of suffering from back pain. In addition to these cross-sectional results, a longitudinal study examined the causal relations between recovery and LBP. In this study, Machin and Hoare [50] reported a significant predictive influence of higher need for recovery on physical complaints in bus drivers. Overall, these 1st results indicate a relevance of recovery processes for physical health issues, including LBP. People with a higher need of recovery tend to have or develop physical complaints more often. Furthermore, the moderating influence of recovery on the relation of work factors and LBP has been indicated in one of these studies.

\section{INFLUENCES OF RECOVERY ON LBP DEVELOPMENT}

Based on the previous considerations, 2 ways by which recovery might influence the impact of straining work conditions on LBP development can be distinguished. On the one hand, recovery has a preventive function. Work demands would not be perceived as highly straining if one was well-recovered and only low acute load reactions would occur. A well-recovered person is more capable of dealing with high amounts of stress without perceiving excessive acute load reactions. The influences of relevant risk factors are diminished, likewise are the risk of developing LBP.

On the other hand, recovery has a restoring function, which is especially important to avoid accumulation of stress over time. The fact that recovery moderates the influence of work strain on health, especially when work strain is high, is in line with the 'scissor model' of Kellmann [25]. After exposure to highly straining work conditions, sufficient recovery is necessary to restore physical and psychological systems. One should stop rumination and try to avoid further demands. If one cannot return to the initial state, upcoming working demands will be perceived as even more straining and thus the accumulation of stress could take place.

In summary, recovery has a protective and restoring function, both of which lead to a reduced risk of experiencing high amounts of stress, as described in Figure 3. Consequently, the LBP risk will be reduced, since influences of LBP risk factors are decreased. A moderating influence 


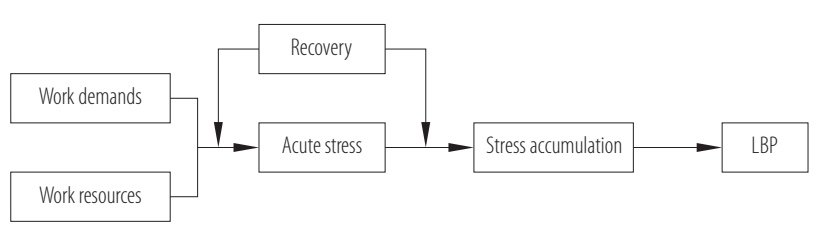

Fig. 3. The protective and restoring influence of recovery on low back pain (LBP) development, caused by work factors

of recovery on the relation between work strain and LBP development can be assumed. As described, recovery mainly influences the impact of work strain on health when work strains are high. This means recovery will have little or no influence on the LBP risk when work demands are low; however, if work demands are high, recovery is highly relevant to reduce stress and the risk of LBP development. Consequently, people confronted with high work strain should increase their recovery experiences in leisure time, even though it is harder to relax under stress.

The final theoretical model reflects the 1st attempt to integrate recovery processes in the pathogenesis of LBP. Although the interplay of work conditions, recovery, and health, has already been described in several theoretical concepts, no longitudinal study has been published regarding possible moderating influences of recovery on LBP risk, caused by work conditions. So far, possible interrelations between LBP risk factors, recovery and LBP development can only be derived from studies regarding general physical health complaints. This is astonishing given that stress should never be examined without looking for possible moderating recovery processes [51].

\section{CONCLUDING REMARKS}

The presented results and derived theoretical model illustrate the influence of recovery on the impact of psychosocial work factors on LBP development. According to this model, recovery influences the LBP risk by either preventing a strong stress reaction towards demanding work conditions or stopping ongoing load reactions and restoring depleted physical and psychological systems. Whereas the role of recovery for work-induced LBP development could be described in this paper in general, specific relationships between related parameters remain unclear and should be investigated in future studies.

The considerations contained in this paper highlight the importance of recovery processes for LBP development. People with high work strain and low recovery experiences tend to develop LBP more often compared to those with high work strain and high recovery experiences or people with general low work strain. This theoretically deduced moderating effect of recovery has to be supported by research results. Studies including measures of psychosocial work factors, recovery parameters, and back pain could provide more insight into possible moderating effects of recovery. Prospective studies should be executed to clarify the exact connections and directions between the involved factors. At present, it is unclear how strong these moderating effects of recovery might be. It would also be interesting to investigate which psychosocial work factors are specifically influenced by recovery, or alternatively, whether recovery influences all work factors in similar ways.

To gain a better understanding of how recovery influences LBP development, it would be useful to compare effects of different recovery experiences or forms. A specification of the distinct effects would be useful to identify people at risk and improve LBP prevention. While the effect of recovery activities has been shown to be highly subjective [25], Sonnentag and Fritz [52] indicated 4 basic recovery experiences that are important for successful recovery: Detachment, Relaxation, Control, and Mastery. It is unclear which recovery experience is most important to reduce LBP risk when confronted with high stress. A specification of the interrelations between work factors and recovery experiences will provide further insight into the fundamental mechanisms through which recovery reduces work strain and LBP risk. According to Kellmann and Kallus [26], recovery can take place in different forms. Beside general recovery, social recovery, physical recovery, success, and sleep can be 
distinguished as well. Similar to various recovery experiences, differences between those recovery forms as regards LBP development should be investigated. Is high social recovery especially important for employees with low social support at work, or is a specification of the recovery forms irrelevant for the impact on work strain and LBP risk? If the hypothesized moderating effect of recovery can be confirmed by empirical research, it will enrich the knowledge on the factors related to LBP development. Moreover, it could promote new approaches in LBP prevention with a stronger focus on teaching techniques to cope with straining work conditions. Whereas employers should strive to reduce unfavorable and straining work conditions to minimize LBP risk for employees, teaching employees ways to recover after and during work may also be an effective way to reduce LBP risk.

\section{ACKNOWLEDGMENTS}

We would like to thank Julian Fritsch and Max Pelka for their helpful comments on previous versions of this article.

\section{REFERENCES}

1. Hoy D, Bain C, Williams G, March L, Brooks P, Blyth F, et al. A systematic review of the global prevalence of low back pain. Arthritis Rheum. 2012;64(6):2028-37, http://dx. doi.org/10.1002/art.34347.

2. Asche CV, Kirkness CS, McAdam-Marx C, Fritz JM. The societal costs of low back pain: Data published between 2001 and 2007. J Pain Palliat Care Pharmacother. 2007;21(4):2533, http://dx.doi.org/10.1300/J354v21n04_06.

3. Maetzel A, Li L. The economic burden of low back pain: A review of studies published between 1996 and 2001. Best Pract Res Clin Rheumatol. 2002;16(1):23-30, http://dx.doi. org/10.1053/berh.2001.0204.

4. Dagenais S, Caro J, Haldeman S. A systematic review of low back pain cost of illness studies in the United States and internationally. Spine. 2008;8(1):8-20, http://dx.doi.org/10.10 16/j.spinee.2007.10.005.
5. Marras WS. The future of research in understanding and controlling work-related low back disorders. Ergonomics. 2005;48(5):464-77, http://dx.doi.org/10.1080/0014013 0400029175.

6. Heneweer H, Staes F, Aufdemkampe G, van Rijn M, Vanhees L. Physical activity and low back pain: A systematic review of recent literature. Eur Spine J. 2011;20(6):826-45, http://dx.doi.org/10.1016/j.pain.2008.12.033.

7. Hauke A, Flintrop J, Brun E, Rugulies R. The impact of workrelated psychosocial stressors on the onset of musculoskeletal disorders in specific body regions: A review and meta-analysis of 54 longitudinal studies. Work Stress. 2011;25(3):243-56, http://dx.doi.org/10.1080/02678373.2011.614069.

8. Lang J, Ochsmann E, Kraus T, Lang JW. Psychosocial work stressors as antecedents of musculoskeletal problems: A systematic review and meta-analysis of stability-adjusted longitudinal studies. Soc Sci Med. 2012;75(7):1163-74, http:// dx.doi.org/10.1016/j.socscimed.2012.04.015.

9. Clays E, de Bacquer D, Leynen F, Kornitzer M, Kittel F, de Backer G. The impact of psychosocial factors on low back pain: Longitudinal results from the Belstress study. Spine. 2007;32(2):262-68, http://dx.doi.org/10.1097/01.brs. 0000251884.94821.c0.

10. Ghaffari M, Alipour A, Farshad A, Jensen I, Josephson M, Vingard E. Effect of psychosocial factors on low back pain in industrial workers. Occup Med. 2008;58(5):341-47, http:// dx.doi.org/10.1093/occmed/kqn006.

11. Lonnberg F, Pedersen PA, Siersma V. Early predictors of the long-term outcome of low back pain-results of a 22-year prospective cohort study. Fam Pract. 2010;27(6):609-14, http:// dx.doi.org/10.1093/fampra/cmq061.

12. Miranda H, Viikari-Juntura E, Punnett L, Riihimaki H. Occupational loading, health behavior and sleep disturbance as predictors of low-back pain. Scand J Work Environ Health. 2008;34(6):411-19, http://dx.doi.org/10.5271/sjweh.1290.

13. Marras WS. The working back: A systems view. Hoboken(NJ): Wiley-Interscience; 2008, http://dx.doi.org/10.1002/ 9780470258576. 
14. Antonovsky A. Unraveling the mystery of health: How people manage stress and stay well. 1st ed. San Francisco: Jossey-Bass; 1987.

15. Geurts SAE, Sonnentag S. Recovery as an explanatory mechanism in the relation between acute stress reactions and chronic health impairment. Scand J Work Environ Health. 2006;32(6):482-92, http://dx.doi.org/10.5271/sjweh.1053.

16. Meijman TF, Mulder G. Psychological aspects of workload. In: Drenth PJD, Thierry H, de Wolff CJ, editors. Work psychology: Handbook of work and organizational psychology. 2nd ed. Hove: Psychology Press; 1998. p. 5-33.

17. Bakker AB, Demerouti E. The job demands-resources model: State of the art. J Manag Psychol. 2007;22(3):309-28, http://dx.doi.org/10.1097/BRS.0b013e318195b257.

18. Brage S, Sandanger I, Nygard JF. Emotional distress as a predictor for low back disability: A prospective 12-year population-based study. Spine. 2007;32(2):269-74, http:// dx.doi.org/10.1097/01.brs.0000251883.20205.26.

19. Jansen JP, Morgenstern H, Burdorf A. Dose-response relations between occupational exposures to physical and psychosocial factors and the risk of low back pain. Occup Environ Med. 2004;61(12):972-9, http://dx.doi.org/10.1136/ oem.2003.012245.

20. Vandergrift JL, Gold JE, Hanlon A, Punnett L. Physical and psychosocial ergonomic risk factors for low back pain in automobile manufacturing workers. Occup Environ Med. 2011;69(1):29-34, http://dx.doi.org/10.1136/ oem.2010.061770.

21. Eriksen HR, Ihlebæk C, Jansen JP, Burdorf A. The relations between psychosocial factors at work and health status among workers in home care organizations. Int J Behav Med. 2006;13(3):183-92, http://dx.doi.org/10.1136/ oem.2003.008482.

22. Yip YB, Ho SC. Effects of socio-psychological stress on new and recurrent low back pain among Chinese community middle-aged women. Psychol Health Med. 2001;6(4):36172, http://dx.doi.org/10.1080/13548500126533.
23. Thorbjornsson CO, Alfredsson L, Fredriksson K, Koster M, Michelsen H, Vingard E, et al. Psychosocial and physical risk factors associated with low back pain: A 24 year follow up among women and men in a broad range of occupations. Occup Environ Med. 1998;55(2):84-90, http://dx.doi. org/10.1136/oem.55.2.84.

24. McEwen BS. Stress, adaptation, and disease: Allostasis and allostatic load. Ann N Y Acad Sci. 1998;840(1):33-44, http:// dx.doi.org/10.1111/j.1749-6632.1998.tb09546.x.

25. Kellmann M. Underrecovery and overtraining: Different concepts - similar impact? In: Kellmann M, editor. Enhancing recovery: Preventing underperformance in athletes. Champaign: Human Kinetics; 2002. p. 3-24.

26. Kellmann M, Kallus KW. Recovery-Stress Questionnaire for Athletes: User manual. Champaign: Human Kinetics; 2001.

27. Tucker P, Dahlgren A, Akerstedt T, Waterhouse J. The impact of free-time activities on sleep, recovery and well-being. Appl Ergon. 2008;39(5):653-62, http://dx.doi.org/10. 1016/j.apergo.2007.12.002.

28. Sonnentag S, Zijlstra FRH. Job characteristics and off-job activity as predictors of need for recovery, well-being, and fatigue. J Appl Psychol. 2006;91(2):330-50, http://dx.doi. org/10.1037/0021-9010.91.2.330.

29. van der Hulst M, van Veldhoven M, Beckers D. Overtime and need for recovery in relation to job demands and job control. J Occup Health. 2006;48(1):11-19, http://dx.doi. org/10.1539/joh.48.11.

30. Binnewies C, Sonnentag S, Mojza EJ. Recovery during the weekend and fluctuations in weekly job performance: A week-level study examining intra-individual relationships. J Occup Organ Psychol. 2010;83(2):419-41, http://dx.doi. org/10.1348/096317909X418049.

31. Fritz C, Yankelevich M, Zarubin A, Barger P. Happy, healthy, and productive: The role of detachment from work during nonwork time. J Appl Psychol. 2010;95(5):977-83, http://dx.doi.org/10.1037/a0019462.

32. Siltaloppi M, Kinnunen U, Feldt T. Recovery experiences as moderators between psychosocial work characteristics and 
occupational well-being. Work Stress. 2009;23(4):330-48, http://dx.doi.org/10.1080/02678370903415572.

33. White E. Helping to promote psychological well-being at work: The role of work engagement, work stress and psychological detachment using the job demands-resources model. The Plymouth Student Scientist. 2010;4(2):155-80.

34. Fritz C, Sonnentag S. Recovery, well-being, and performance-related outcomes: The role of workload and vacation experiences. J Appl Psychol. 2006;91(4):936-45, http:// dx.doi.org/10.1037/0021-9010.91.4.936.

35. Fritz C, Sonnentag S, Spector PE, McInroe JA. The weekend matters: Relationships between stress recovery and affective experiences. J Organ Behav. 2010;31(8):1137-62, http://dx.doi.org/10.1002/job.672.

36. Binnewies C, Sonnentag S, Mojza EJ. Daily performance at work: Feeling recovered in the morning as a predictor of day-level job performance. J Organ Behav. 2009;30(1): 67-93, http://dx.doi.org/10.1002/job.541.

37. Fritz C, Sonnentag S. Recovery, health, and job performance: Effects of weekend experiences. J Occup Health Psychol. 2005;10(3):187-99, http://dx.doi.org/10.1037/10768998.10.3.187.

38. Kivimaki M, Leino-Arjas P, Kaila-Kangas L, Luukkonen R, Vahtera J, Elovainio M, et al. Is incomplete recovery from work a risk marker of cardiovascular death? Prospective evidence from industrial employees. Psychosom Med. 2006;68(3):402-7, http://dx.doi.org/10.1097/01. psy.0000221285.50314.d3.

39. van Amelsvoort LG, Kant IJ, Bultmann U, Swaen GMH. Need for recovery after work and the subsequent risk of cardiovascular disease in a working population. Occup Environ Med. 2003;60 Suppl 1:i83-7, http://dx.doi.org/10.1136/ oem.60.suppl_1.i83.

40. Sluiter JK, Frings-Dresen MH, van der Beek AJ, Meijman TF. The relation between work-induced neuroendocrine reactivity and recovery, subjective need for recovery, and health status. J Psychosom Res. 2001;50(1):29-37, http://dx.doi.org/10.1016/S0022-3999(00)00213-0.
41. Sluiter JK, de Croon EM, Meijman TF, Frings-Dresen MH. Need for recovery from work related fatigue and its role in the development and prediction of subjective health complaints. Occup Environ Med. 2003;60(1):62-70, http:// dx.doi.org/10.1136/oem.60.suppl_1.i62.

42. Shiri R, Karppinen J, Leino-Arjas P, Solovieva S, ViikariJuntura E. The association between smoking and low back pain: A meta-analysis. Am J Med. 2010;123(1):87.e7-35, http://dx.doi.org/10.1016/j.amjmed.2009.05.028.

43. Swaen GMH, van Amelsvoort LG, Bültmann U, Kant IJ. Fatigue as a risk factor for being injured in an occupational accident: Results from the Maastricht cohort study. Occup Environ Med. 2003;60 Suppl 1:i88-92, http://dx.doi. org/10.1136/oem.60.suppl_1.i88.

44. Brink MS, Visscher C, Arends S, Zwerver J, Post WJ, Lemmink KA. Monitoring stress and recovery: New insights for the prevention of injuries and illnesses in elite youth soccer players. Br J Sports Med. 2010;44(11):809-15, http://dx.doi. org/10.1136/bjsm.2009.069476.

45. Eibel K, Iwanowa A, Jimenez P, Kallus W, Korunka C, Kubicek B. [Working life quality of older employees]. Vienna: Bundesarbeitskammer; 2009. German.

46. de Croon EM, Sluiter JK, Frings-Dresen MH. Need for recovery after work predicts sickness absence. J Psychosom Res. 2003;55(4):331-9, http://dx.doi.org/10.1016/S0022-3999 (02)00630-X.

47. Sonnentag S, Binnewies C, Mojza EJ. Staying well and engaged when demands are high: The role of psychological detachment. J Appl Psychol. 2010;95(5):965-76, http://dx. doi.org/10.1037/a0020032.

48. de Jonge J, Spoor E, Sonnentag S, Dormann C, van den Tooren M. "Take a break?!" Off-job recovery, job demands, and job resources as predictors of health, active learning, and creativity. Eur J Work Organ Psychol. 2012;21(3):321-48, http://dx.doi.org/10.1080/135943 2X.2011.576009.

49. Mierswa T, Kellmann M. [Psychosocial work factors and back pain: The moderating effects of detachment in 
leisure time]. Z Gesundh. 2014;22(3):129-49, http://dx.doi. org/10.1026/0943-8149/a000121. German.

50. Machin MA, Hoare PN. The role of workload and driver coping styles in predicting bus drivers' need for recovery, positive and negative affect, and physical symptoms. Anxiety Stress Coping. 2008;21(4):359-75, http://dx.doi. org/10.1080/10615800701766049.
51. Kallus KW. [The Recovery-Stress Questionnaire]. Frankfurt am Main: Swets \& Zeitlinger; 1995. German.

52. Sonnentag S, Fritz C. The recovery experience questionnaire: Development and validation of a measure for assessing recuperation and unwinding from work. J Occup Health Psychol. 2007;12(3):204-21, http://dx.doi.org/10.1037/10768998.12.3.204.

This work is available in Open Access model and licensed under a Creative Commons Attribution-NonCommercial 3.0 Poland License - http://creativecommons.org/ licenses/by-nc/3.0/pl/deed.en. 